\title{
BMJ Open 'I'm not a druggie, I'm just a diabetic': a qualitative study of stigma from the perspective of adults with type 1 diabetes
}

\author{
Jessica L Browne, ${ }^{1,2}$ Adriana Ventura, ${ }^{1,3}$ Kylie Mosely, ${ }^{4}$ Jane Speight ${ }^{1,2,5}$
}

To cite: Browne JL, Ventura A, Mosely K, et al. 'I'm not a druggie, I'm just a diabetic': a qualitative study of stigma from the perspective of adults with type 1 diabetes. BMJ Open 2014;4:e005625.

doi:10.1136/bmjopen-2014005625

- Prepublication history for this paper is available online. To view these files please visit the journal online (http://dx.doi.org/10.1136/ bmjopen-2014-005625).

Received 6 May 2014 Revised 8 July 2014 Accepted 9 July 2014

CrossMark

For numbered affiliations see end of article.

Correspondence to Dr Jessica L Browne; jbrowne@acbrd.org.au

\section{ABSTRACT}

Objectives: While health-related stigma has been the subject of considerable research in other conditions (eg, HIV/AIDS, obesity), it has not received substantial attention in diabetes. Our aim was to explore perceptions and experiences of diabetes-related stigma from the perspective of adults with type 1 diabetes mellitus (T1DM).

Design: A qualitative study using semistructured interviews, which were audio recorded, transcribed and subject to thematic analysis.

Setting: All interviews were conducted in non-clinical settings in metropolitan areas of Victoria, Australia.

Participants: Adults aged $\geq 18$ years with T1DM living in Victoria were eligible to take part. Participants were recruited primarily through the state consumer organisation representing people with diabetes. A total of 27 adults with T1DM took part: 15 (56\%) were women; median IQR age was 42 (23) years and diabetes duration was 15 (20) years).

Results: Australian adults with T1DM perceive and experience T1DM-specific stigma as well as stigma-byassociation with type 2 diabetes. Such stigma is characterised by blame, negative social judgement, stereotyping, exclusion, rejection and discrimination. Participants identified the media, family and friends, healthcare professionals and school teachers as sources of stigma. The negative consequences of this stigma span numerous life domains, including impact on relationships and social identity, emotional wellbeing and behavioural management of T1DM. This stigma also led to reluctance to disclose the condition in various environments. Adults with T1DM can be both the target and the source of diabetes-related stigma.

Conclusions: Stigmatisation is part of the social experience of living with T1DM for Australian adults. Strategies and interventions to address and mitigate this diabetes-related stigma need to be developed and evaluated.

\section{INTRODUCTION}

Health-related stigma is the negative social judgement based on a feature of a condition or its management that leads to perceived or

\section{Strengths and limitations of this study}

- To our knowledge, this study is the first to conduct a systematic and in-depth examination of the perception and experience of diabetesrelated stigma from the perspective of adults with type 1 diabetes mellitus.

- Strengths of this study include the novelty of the topic of enquiry, and the richness of data collected through in-depth interviewing.

- Limitations of this study include the fact that people born outside Australia and those living in rural/regional areas were under-represented in our sample.

experienced exclusion, rejection, blame, stereotyping and/or status loss. ${ }^{12}$ This is a destructive social phenomenon; one that has been observed and studied extensively in conditions such as HIV/AIDS, ${ }^{3-5}$ obesity, ${ }^{6-9}$ and mental illness. ${ }^{10-14}$ Type 1 diabetes mellitus (T1DM) is a serious chronic condition that requires unrelenting self-management (including multiple daily insulin injections or insulin pump therapy), and can impact on both quantity and quality of life. Traditionally, T1DM research has focused on the biomedical aspects of aetiology and management of the condition. However, recent decades have witnessed the rise of psychosocial research, exploring the emotional, behavioural and social aspects of living with T1DM. $^{15}$

There is limited but growing awareness that people with diabetes face stigmatisation and discrimination as a result of their condition. The International Diabetes Federation has identified diabetes-related stigma as a problem that needs urgent attention, and one of the organisation's key priorities is to 'champion a world free from discrimination and stigma for people with diabetes' (ref. 16, p.10). A recent large-scale multinational 
survey found that one in five people with diabetes reported having experienced discrimination, ${ }^{17}$ which is one example of how stigmatisation can manifest. However, our recent review highlighted that the body of research exploring diabetes-related stigma specifically is relatively small. ${ }^{18}$

Our recent interview study of people with type 2 diabetes mellitus (T2DM) found that most felt stigmatised as a result of having T2DM, as was evident in feeling blamed by others for causing their condition, being subject to negative stereotyping, or being discriminated against. ${ }^{19}$ People with T2DM perceived that those with T1DM were not stigmatised. ${ }^{19}$ In the current study, we aimed to investigate this issue from the perspective of people with T1DM to explore their perceptions of diabetes-related stigma, their experiences of such stigma and the extent to which these were similar to or differed from the experiences of people with T2DM.

\section{METHODS}

Study design

We conducted semistructured, in-depth interviews with 27 adults with T1DM to explore their perceptions and experiences of diabetes-related stigma.

\section{Participants and recruitment}

Adults with T1DM, aged $\geq 18$ years, who could understand and speak English and who lived in the Australian state of Victoria were eligible to participate in this interview study. The primary method of participant recruitment was via an email that was distributed to the membership list of Diabetes Australia-Vic (DA-Vic; the peak consumer body representing people affected by diabetes in Victoria, Australia). The study was also advertised state-wide in diabetes-related media and social media. The study was described as an investigation of 'the social experience of living with type 1 diabetes'. The term 'stigma' was not used in study advertisements so as to reduce the risk of biasing the study by attracting only participants with extreme negative experiences.

A total of 79 people enquired about the study, of whom three did not meet study inclusion criteria and 76 were sent study information sheets. Purposive sampling was used to ensure a gender balance, and a wide range of ages and diabetes durations. Although the study was advertised state-wide and interviews could be arranged in regional areas, all study participants lived in Melbourne. A total of 27 adults with T1DM were recruited and took part in interviews.

\section{Interview schedule and procedure}

We used a semistructured interview schedule which closely followed that used in our previous interview study with people with T2DM. ${ }^{19}$ The schedule was designed to elicit participant narratives of perceived or experienced diabetes-related stigma. Interviewers invited participants to discuss their own social experience of living with
T1DM in a range of contexts, including healthcare settings, the workplace, their social and/or family environments and in the media. Interviewers did not refer to 'stigma' explicitly until either the participant had used it spontaneously, or until the last interview questions which addressed the concept directly. This approach was used to avoid confusing participants with jargon, and to avoid introducing bias in the questioning, thus maximising opportunities for participants to discuss their positive and negative social experiences.

Two experienced interviewers with postgraduate training in health psychology (JLB and AV) conducted the interviews. Nine interviews were performed by one interviewer and observed by the other. This was performed to facilitate reflective discussions about interview content and the role and influence of the interviewer during the interview, as well as for quality assurance purposes. The remaining interviews were conducted by a sole interviewer. Interviewers wrote notes and reflections immediately after each interview. During the first interview of the study, the interviewers observed that the participant was reluctant to freely discuss their views about people with T2DM. In an attempt to relieve any anxiety participants may have felt about offending or upsetting the interviewer, the interviewers disclosed to all subsequent participants that they themselves did not have any type of diabetes.

All interviews were conducted in non-clinical settings, were audio recorded, and lasted an average of $59 \mathrm{~min}$ (range: 28-100 $\mathrm{min}$ ). Participants also completed a short questionnaire to provide demographic and clinical information. All data were anonymised, with a participant ID number used to match audio files and questionnaires. Participants received a \$A20 (£11; €14; US\$19) department store gift voucher as a token of appreciation for taking part in the study.

\section{Transcription and analysis}

A professional transcription service was used to transcribe audio recordings verbatim. Transcripts were checked against the recordings for accuracy, and then imported into NVivo V.10 for data coding and analysis.

Data were analysed using inductive thematic analysis. ${ }^{20}$ $\mathrm{AV}$ and JLB read and re-read the transcripts to develop an initial coding framework with detailed definitions and coding rules, which they then piloted on three interviews independently. The draft framework was then reviewed by the whole research team, and amended collaboratively to improve utility and comprehensibility. Following this, JLB and AV used the revised framework to code three transcripts together to ensure agreement, and then coded an additional five transcripts independently. Intercoder agreement (calculated based on the analysis of the five transcripts coded independently) for each code was determined by summing the percentage of content in each code identified by both coders and the percentage of content in each code identified by neither coder. A mean agreement rating (averaging 
agreement ratings across codes) of $99.0 \%$ was achieved for the five transcripts, indicating a high level of consistency in coding decisions. Minor discrepancies were resolved through discussion, raising the agreement level to $100 \%$. AV then coded the remaining 19 transcripts independently. Once transcripts had been coded, the content of each code was examined to identify overlapping or redundant codes and relationships between codes.

\section{RESULTS}

\section{Sample characteristics}

A total of 27 adults with T1DM took part in this study. Slightly more than half $(n=15,56 \%)$ were women. The median age was 42 years (range $20-68$ years; $I Q R=23$ ), and median diabetes duration was 15 years (range $5-43$ years; $I Q R=20)$. Four participants $(15 \%)$ were born outside Australia, which is a somewhat lower proportion compared to the general population of Australian adults with diabetes $(25 \%){ }^{21}$ Further sample characteristics are displayed in table 1 .

\section{Perceptions of social stigma}

Almost all participants $(\mathrm{n}=25 ; 93 \%)$ indicated that they believed T1DM was a stigmatised condition; with 14 (52\%) indicating they had experienced stigmatisation directly and the remainder describing the stigma as a phenomenon they perceived in society more generally. The two participants who did not believe T1DM was stigmatised both commented that they perceived that the stigma associated with T1DM has disappeared or lessened over time, as society has become more educated about and understanding of the condition; they added

\begin{tabular}{lc}
$\begin{array}{l}\text { Table } 1 \text { Demographic and clinical characteristics of } \\
\text { participants (N=27) }\end{array}$ \\
\hline \multicolumn{2}{l}{ Median, } \\
Sample characteristics & IQR or $\mathbf{n}(\%)$ \\
\hline Age (years) & 42,23 \\
Diabetes duration (years) & 15,20 \\
Gender (women) & $15(56)$ \\
Primary treatment & \\
Insulin pump therapy & $16(59)$ \\
Insulin injections & $11(41)$ \\
Highest qualification & \\
School or intermediate certificate & $0(0)$ \\
High school or leaving certificate & $4(15)$ \\
Trade/apprenticeship & $2(7)$ \\
Certificate/diploma & $8(30)$ \\
Bachelor degree or higher & $13(48)$ \\
Employment & \\
Full-time work & $10(37)$ \\
Part-time work & $4(15)$ \\
Retired/not working & $13(48)$ \\
Born in Australia & $22(85)$ \\
English language & $27(100)$ \\
\hline
\end{tabular}

that the dominant stigma now was associated with T2DM, not T1DM.

Four $(15 \%)$ participants used the words 'stigma/stigmatised/stigmatisation' to describe the experience of living with T1DM before the interviewer explicitly used this phrase, and another $19 \quad(76 \%)$ participants described evidence of T1DM stigmatisation, or used similar or related phrases (eg, 'discrimination'), without using the word 'stigma' specifically. Two (7\%) participants only described the stigma around T1DM when explicitly asked by the interviewer, and two (7\%) reported that they did not believe T1DM to be a stigmatised condition.

Table 2 summarises the themes and subthemes identified in our analysis, and indicates the number of participants, and which participants, contributed data relevant to each theme. Participants described both stigma-byassociation with T2DM, and T1DM-specific stigma. They described negative consequences of stigma across numerous life domains. It was evident that adults with T1DM can be both the target and the source of diabetes-related stigma. Data saturation (ie, no new themes emerging) was reached at the ninth interview, though purposive sampling continued to ensure a varied sample. Findings are illustrated by selected participant quotes.

\section{Evidence of diabetes-related stigma \\ Stigma by association}

The most salient form of diabetes-related stigma was stigma by association with T2DM. Participants were quick to identify that much of the stigmatisation they perceived or experienced as people with T1DM was the result of misplaced negative judgement of T2DM. They believed this reflected a lack of knowledge in the community about the different types and causes of diabetes. This led to feelings of annoyance, frustration, anger and even hatred.

People just assume that you're young and you look healthy so they can't get their head around how 'actually you must be really unhealthy to be on insulin and it must be partly your own fault' and they're thinking that you're type 2 and that misapprehension I found really frustrating $\ldots$ the level of judgment that goes with it. (\#18, woman, age 29)

I know some diabetics who just hate type 2s. (\#23, man, age 20)

Participants had strong feelings about the need to distinguish between T1DM and T2DM, even suggesting a change of name would be helpful. Reasons for this included wanting to distance themselves from those with T2DM so as to avoid the negative judgements and stereotypes (eg, 'fat', 'lazy', 'eat too much'), wanting people to understand the seriousness of T1DM as a health condition and wanting to educate others about the causes of the various types of diabetes. 

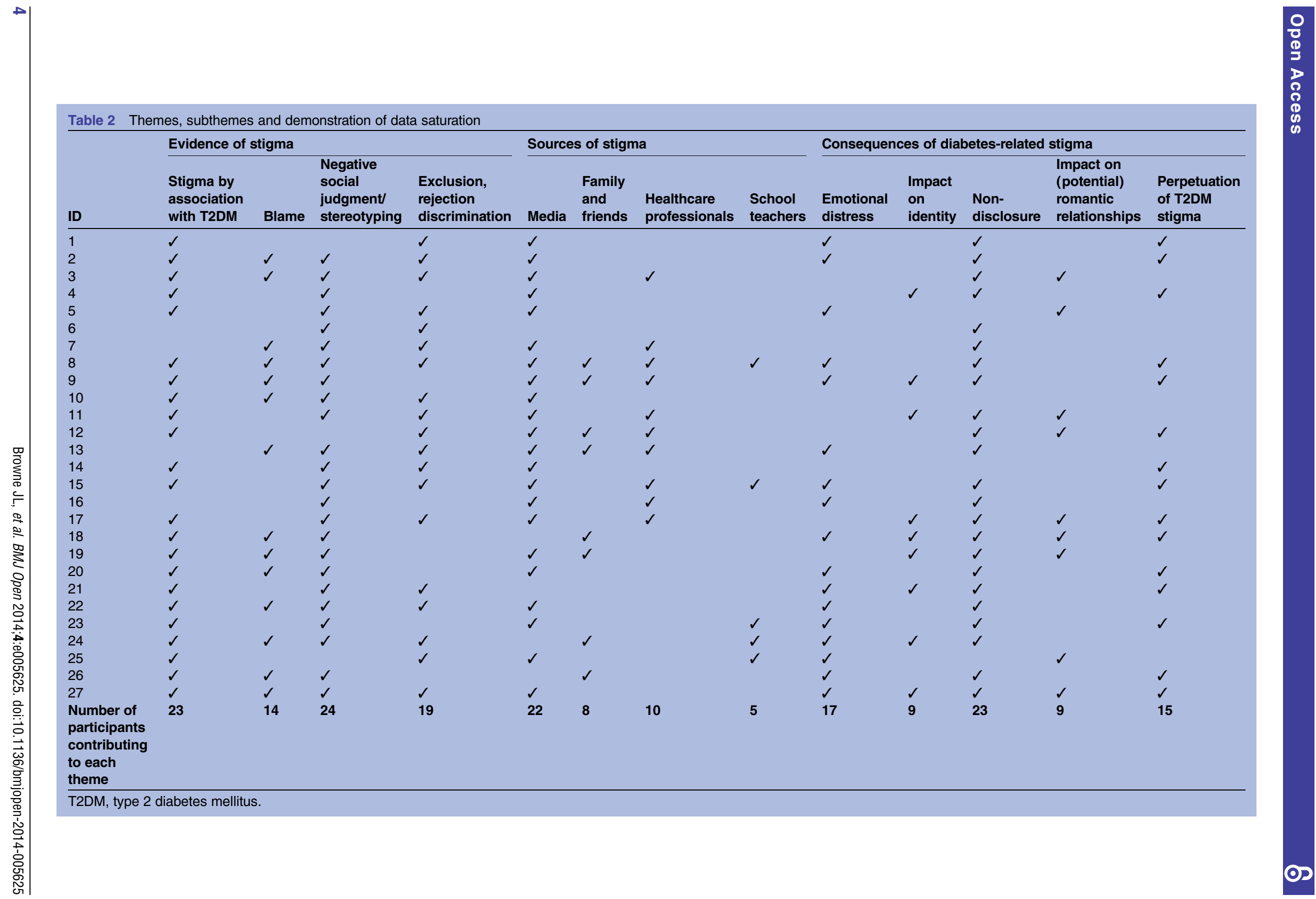

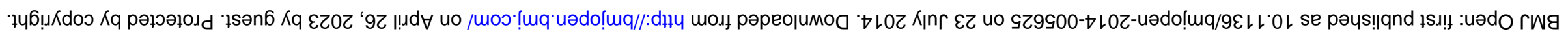


Look, I've got nothing against type 2 but I'm not a type

2, I'm a type 1 and there's a societal stigma attached to being a type 2, you brought it on yourself, you're fat, you're unfit, this, that and the other. I don't want to be associated with that. (\#4, man, age 52)

\section{Blame}

Participants reported being blamed by others, especially family and health professionals, when it was perceived that they were not managing their diabetes optimally. Examples of behaviour that prompted others to judge them in this way were eating sweet foods, having a severe hypoglycaemic event (very low blood glucose levels), gaining weight, and developing diabetes-related complications.

It seems as though with low blood sugars you get blamed as being irresponsible all the time 'Why didn't you bring anything to eat? Why didn't you check your sugar levels before you left? Why didn't you do this, why didn't you do that?'... sometimes perhaps I forget or I'm ill prepared but it's not intentional. (\#26, man, age 51)

Blame was also experienced as the result of other people's perceptions that diabetes is a lifestyle condition caused by poor eating habits, being overweight and inactivity. Participants found this to be frustrating and unfair; they believed it reflected confusion (or a lack of sophistication in the understanding) in society about T1DM and T2DM, or a misconception that diabetes is caused by consuming too much sugar.

People with type 1 could be blamed, as if 'if you'd had a better lifestyle you wouldn't have this' and it's nothing to do with that. (\#10, woman, age 64)

\section{Negative social judgments and stereotyping}

Participants described some form of negative social judgment or stereotyping associated with T1DM. Common stereotypes were that T1DM is a condition of childhood (and, by implication, all adults with diabetes have T2DM), that T1DM is the 'bad' kind of diabetes, that is, more serious, being sickly, not being able to live a normal and independent life. Participants disliked all of these stereotypes.

...'damaged goods' I guess. People think that you're more broken or damaged or sicker than you really are.

(\#21, woman, age 21)

Participants described being worried about, or having experienced, being mistaken for an illicit drug user while injecting insulin. This was particularly the case for those with a longer duration of T1DM, who recalled having to inject insulin with a vial and a syringe, before insulin pens and pumps were available. Participants were also worried about being considered rude and aggressive, or being mistaken for being drunk, during hypoglycaemia.
I remember quite clearly sitting in a shopping mall doing this [injecting] when I was maybe 10 or 11 years old and having a crowd of people come up and some person commented it was such a disgrace that someone was doing drugs at such an age. (\#11, man, age 29)

There's a real confusion between being drunk and having a hypo...the signs are often similar...if you see somebody behaving like they're out of control, it's easy to dismiss them [as] somebody who lacks control. (\#3, woman, age 52)

\section{Exclusion, rejection and discrimination}

Exclusion, rejection and discrimination were perceived by participants to occur across a number of life domains. As children, participants recalled having been excluded from school activities and bullied or teased in the school playground. As adults, participants had experienced not being invited to social occasions where there was likely to be unhealthy or sugary food, experiencing unwarranted restrictions when planning or taking a flight, having difficulties obtaining various types of insurance and prohibitive driving and licensing rules (in response to new guidelines in Australia). Most salient, however, was the threat of discrimination in the workplace. Participants described a fear of disclosing T1DM in the workplace on the basis that they believed it would harm their job prospects and reported specific incidences where they believed their career advancement was limited as a result of having T1DM.

I told my employer that I had a medical problem and what it was, he wrote back to me and said that he couldn't guarantee my future career, which was a bit of a shock. (\#5, man, age 68)

\section{Sources of stigma}

Role of the media: myths and misconceptions

Participants believed that much of this stigma was the result of a lack of public knowledge and abounding misconceptions about diabetes, which they perceived to be fuelled by the media. Journalistic media, popular culture media, and even health promotion or diabetes awareness campaigns were all perceived as drivers of myths and misconceptions about diabetes, which created or reinforced diabetes-related stigma. Participants had three key criticisms of the media representation of T1DM: i) T1DM rarely receives specific media coverage, with the focus tending to be primarily on T2DM; ii) that when T1DM did receive media coverage, it was often inaccurate; iii) that there was a lack of distinction made between T1DM and T2DM, with much of the coverage referring to 'diabetes' generally.

The one thing that really annoys me is when the media refer to 'diabetes', they don't distinguish between type 1 and type 2 and that really, really upsets me. (\#15, woman, age 43) 


\section{Family and friends}

People closest to the person with T1DM - their family members and friends-were also identified as sources of stigma. Participants reported feeling judged and excluded, and these issues usually centred around food or perceived 'poor management' of diabetes. It was understood that family and friends often had (miscarried) good intentions, but people with T1DM still experienced their behaviour and comments as stigmatising at times.

My brothers would never come and see me if I was in hospital because they would say it would be own fault that I was in there. (\#8, woman, age 21)

\section{Healthcare professionals}

The words and actions of individual healthcare professionals were experienced as stigmatising by some participants. As with family and friends, this resulted in feeling blamed and judged for suboptimal diabetes management and feeling like a failure.

I have in the last two years developed large complications and I have had medical professionals say to me 'well it's your own fault because you're diabetic' which is not what you really want to hear. (\#3, woman, age 52)

\section{School teachers}

Participants who were diagnosed with T1DM as children reflected on some of their negative experiences in school, including not being allowed to eat to treat hypoglycaemia, being singled out as ill or different by teachers in front of classmates and being treated differently with regard to food choices and participation in activities, on school campus and excursions. This resulted in feeling segregated from peers. These memories were highly emotive for participants, even many decades later.

So I felt hugely segregated in primary school and I really hated it so I really didn't want to go on [school] camps. (\#11, man, age 29)

\section{Consequences of stigma}

Emotional distress

Stigmatisation of T1DM led to feelings of dejection, frustration, anger and grief. Participants described being haunted by particular incidents when they had been judged negatively for having T1DM, or for behaviours associated with managing the condition. The emotional distress was most prominent among those who had been living with T1DM for a shorter period of time.

... and you don't forget it. You don't forget the day, the person who said it...it does upset you. (\#13, woman, age 53)

\section{Impact on identity}

Participants perceived that the stigmatisation of T1DM served to define people living with T1DM on the basis of their health condition alone. Consequently, they were motivated to educate others and demonstrate that a person with T1DM can lead a full and successful life. Some expressed a righteous anger about the false assumptions and stigmatisation they faced, and wanted to take a stand against it.

I wouldn't want there to be this special consideration 'wow, and he's a diabetic'. Screw that! I perform really well because I'm a person and I put a lot of effort into it. (\#11, man, age 29)

However, this did not prevent participants from identifying strongly as 'a person with type 1'. This was often carried out in such a way as to distinguish themselves from people with other types of diabetes, most notably those with T2DM.

If you go to my gang of people, we are ferociously type 1.

Type 1 is central to our identity. (\#27, man, age 48)

\section{Non-disclosure}

Participants described their current or past hesitations to disclose the fact that they had T1DM to others. Most common were reservations about disclosing in the workplace, described above. Also evident was a reluctance to disclose to new social contacts, especially new romantic partners or potential partners (discussed below). This was driven largely by not wanting to attract attention, not wanting to be seen as different from others and not wanting to jeopardise the opportunity for friendship. Participants described making inconvenient, and sometimes elaborate, plans to ensure they were able to engage in the necessary self-management activities, at the appropriate times, without having to do so in public. Common examples were checking blood glucose and injecting insulin in a toilet cubicle to ensure privacy (which for some resulted in feelings of dirtiness or shame), avoiding swimming or other activities that required that an insulin pump be exposed and planning meetings or other activities around the time of day when hypoglycaemia was likely to occur.

I literally used to excuse myself, go to the toilet, inject myself in a cubical and come back and sit down. I'd feel dirty and that wasn't good. (\#4, man, age 52)

\section{Impact on (potential) romantic relationships}

Participants had experienced the termination (or threat of termination) of a romantic relationship apparently as a result of having T1DM. They described being worried about disclosing their T1DM to partners or potential partners, for fear of it negatively impacting the future of the relationship. Some anticipated or experienced the disapproval of their partner's family, which was seen to be a barrier to marriage.

We were talking about getting engaged ... his mother didn't like me because I was a diabetic. She used to turn around to [him] and say 'don't marry [her] she's a 
responsibility, she will drag you down, she will get sick'. (\#12, woman, age 44)

When I started getting older, like in my $20 \mathrm{~s}$, I used to hide it from any boyfriends that I started to see ... I just thought that maybe not everyone wants a sick girlfriend. (\#9, woman, age 33)

\section{Perpetuation of T2DM stigma}

In general, participants expressed somewhat negative attitudes towards, and beliefs about, people with T2DM. This included stereotypes such as 'lazy', 'fat', 'overconsume', 'sedentary', 'unfit' and judgment about the intelligence and character of people with T2DM, and blame for 'bringing it on themselves'. These attitudes and beliefs served to perpetuate, and give voice to, the stigma surrounding T2DM and drove an in-group/outgroup (or 'us vs them') mentality.

You've got to understand there's two types [of diabetes], there's the fat lazy type and there's the type that I've got ... I use slightly hostile, derogatory terms about people with type 2 . (\#27, man, age 48)

It was also evident that there was resentment among people with T1DM toward those with T2DM, which stemmed from two main factors: (1) the perception that people with T2DM are responsible for many of the negative connotations that surround diabetes, and (2) the perception that T2DM, as a largely preventable condition, attracts more attention and therefore gets more resources and support than T1DM. Some participants believed that T1DM was the 'real' or 'serious' type of diabetes, and was more worthy of research attention and investment of societal resources than T2DM.

I'm not a big fan of type 2 s. I've got no time for them really because I see the view as I've tried my hardest and I've got something that I've got no say in and then there's millions of dollars spent on people that could have prevented it. (\#8, woman, age 21)

\section{DISCUSSION}

To our knowledge, this is the first in-depth investigation of the experiences and perceptions of diabetes-related stigma from the perspective of people living with T1DM. Our literature review found that previous research has perceived diabetes to be an unstigmatised condition, ${ }^{22}$ while our previous qualitative study of people with T2DM found that while they experienced T2DM-related stigma, they assumed that people with T1DM did not experience stigmatisation. ${ }^{19}$ The findings of our current study challenge these assumptions by revealing that stigmatisation is part of the social experience of living with T1DM for Australian adults.

People with T1DM: targets and sources of stigma

Almost all participants in the current study reported that they perceived or experienced diabetes-related stigma, most saliently experienced as stigma-by-association (ie, with T2DM). Our previous research revealed that there is a strong and pervasive social stigma surrounding T2DM, resulting in blame, judgment, stereotyping and restricted life opportunities. ${ }^{19}$ The underlying assumption that drives this stigma is the notion that T2DM is self-inflicted, reflecting negatively on personal character. The current findings indicate that adults with T1DM also perceive, and even (un)intentionally perpetuate this stigma and make every effort to distance themselves from it so as not to be associated with these negative connotations. This was an emotive topic for many participants, and they drew clear in-group (people with T1DM) and out-group (people with T2DM) distinctions. One of the underlying assumptions of social identity theory $^{23}$ is that individuals are intrinsically motivated to achieve a positive self-concept. Adults with T1DM were strongly motivated to clarify their identity and maintain their membership of the 'in-group'. In the face of identity threat, as is experienced when a person with T1DM is assumed by others to have T2DM, adults with T1DM in this study engaged in social competition (social comparison of the in-group with the lower-status out-group), such that people with T1DM favourably compared themselves with people with T2DM on various value dimensions (eg, motivated vs lazy, worthy vs unworthy of support).

Apparent competition for limited resources (eg, healthcare provision, research funding, media attention) can fuel identity threat, while cooperative contact (eg, pursuing or achieving common goals) can bridge the divide. $^{24}$ Diabetes consumer organisations, advocacy groups and opinion leaders with T1DM and T2DM have both a ripe opportunity and a critical responsibility to find ways in which to productively unite the different groups of people with diabetes. Initiatives such as advocacy campaigns designed to reduce diabetes-related stigma may provide an opportunity for people with T1DM and T2DM to work together, and raise awareness of the damage caused by all forms of stigmatisation for people with all types of diabetes.

Australian adults with T1DM identified strongly with the T1DM in-group, largely as a way to differentiate oneself from other groups of people with diabetes. Research in the field of mental illness has indicated that higher illness investment (the extent to which an individual identifies with the condition they have) is associated with worse health outcomes. ${ }^{25}$ However, participants in the current study often reported harnessing their illness investment for the 'greater good', for example, advocacy work or educating others about T1DM.

\section{Implications of T1DM-specific stigma}

Adults with T1DM also perceive and experience stigmatisation that is more specific to their type of diabetes. Participants in the current study reported that they were blamed by others for suboptimal diabetes management, 
or for the perception that they had brought the condition on themselves. While the latter is clearly a misconception, many diabetes-related media campaigns use shocking images or descriptions of diabetes complications which can evoke fear of complications and feelings of guilt. These approaches are often ineffective in facilitating behaviour change $e^{26}$ and further, having these messages in the public domain may influence health professionals, family and friends and the general public to blame, criticise and judge people with diabetes.

Discrimination in the workplace was a common concern for participants in the current study, yet there are few legitimate reasons why adults with T1DM should be disadvantaged occupationally. While severe hypoglycaemia is indeed serious, experiencing such an event at work is a rare occurrence for most people with T1DM, ${ }^{28}$ and having diabetes is not necessarily associated with lower educational attainment or increased workplace absenteeism. ${ }^{29}$ If people with T1DM do not feel comfortable disclosing their condition for fear of negative consequences, they may put their health and safety at risk by delaying essential self-management tasks, or having a severe hypoglycaemic event that their colleagues do not recognise readily (placing them at risk of delayed treatment). It is essential that both employers and employees with T1DM are educated on their rights and responsibilities, and for measures to be in place to support people with T1DM should they need it, without ostracising or restricting them in the workplace.

While previous research has shown that having diabetes can limit marriage prospects, data have only been available for people from South Asian ${ }^{30}$ and African ${ }^{31}$ ethnic backgrounds. Findings from the current study suggest that T1DM can have a negative impact on romantic relationship/marriage prospects for people from a range of ethnic backgrounds, including Caucasian Australians, which has not been recognised previously.
The consequences of T1DM stigma span the emotional, behavioural and social domains. This is largely consistent with our previously proposed framework of diabetes-related stigma, ${ }^{18} 19$ although for participants in the current study, the impact on social relationships and social identity was more pronounced than we anticipated previously. In light of these findings, we have revised our framework of diabetes-related stigma to capture more explicitly the social consequences of perceiving/experiencing stigmatisation, and to identify additional psychological consequences of diabetes-related stigma (dejection, anger, grief). The revised framework is illustrated in figure 1.

\section{Comparison with T2DM study findings}

The results of the current study complement our previous qualitative research with adults with $\mathrm{T} 2 \mathrm{DM},{ }^{19}$ and provide some interesting points of comparison. While both adults with T1DM and T2DM perceived and experienced diabetes-related stigma in the form of blame, negative social judgment and stereotyping, the reasons for the blame, the nature of the judgment and the content of the stereotypes were somewhat different between groups. For adults with T2DM, the issues centred largely on the perception that they brought the condition on themselves and the negative connotations associated with that view, whereas for adults with T1DM the issues and concerns were more nuanced and less homogeneous. This was a reflection of the T1DM group perceiving that they were dealing with both the T2DM stigma, and T1DM-specific stigma.

Another key similarity between the groups was the scathing criticism they both had for the way diabetes was portrayed in the media. The inaccuracies, misconceptions and over-simplifications that they observed in the media were frustrating and upsetting to both people with T1DM and T2DM. Perhaps even more concerning was the perception (shared by both groups) that health

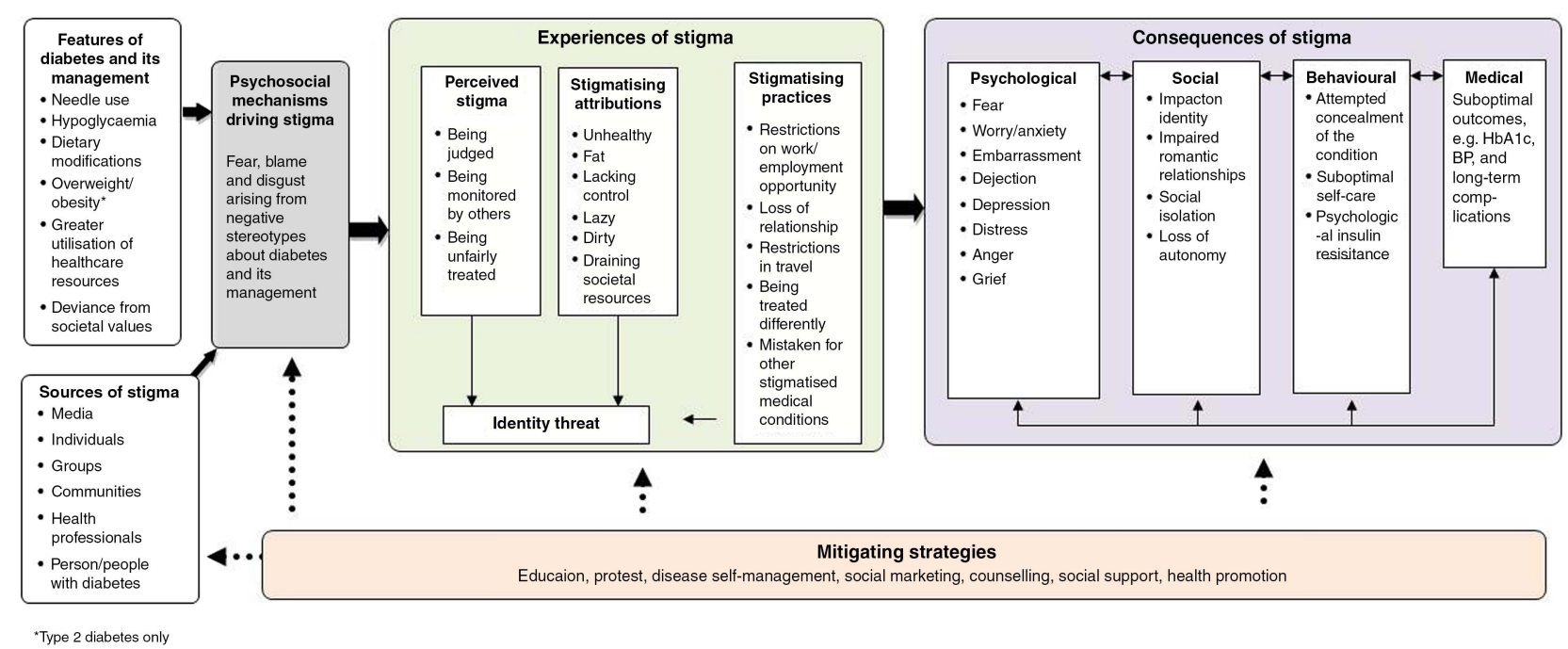

Figure 1 Revised framework to understand diabetes-related stigma. 
promotion and diabetes awareness campaigns, developed by the very consumer organisations intending to serve their needs and represent them, can also act as drivers of diabetes-related stigma.

A distinct difference between the two groups was the experience of shame. For adults with T2DM, the experience of shame was highly salient, ${ }^{19}$ whereas it was not a common experience for adults with T1DM. The shame experienced by those with T2DM was an indication of self-stigmatisation: the internalisation of and acceptance of the stigmatising beliefs. In contrast, adults with T1DM expressed a righteous anger about the stigma they had experienced, did not internalise it, but rather stood in active and vocal opposition against it. These paradoxical responses have been described in detail elsewhere in the context of other conditions such as mental illness ${ }^{32}$ and HIV/AIDS, ${ }^{33}$ and it has been argued that both the perceived legitimacy of the stigmatisation and the extent to which the individual identifies with the stigmatised group are determining factors in self-stigmatisation. ${ }^{32}$ Adults with T1DM generally rejected the legitimacy of the stigmatisation they experienced, and did not identify with people with T2DM who they perceived as being the focus of much of the societal judgment and prejudice. These cognitive responses are likely to protect people with T1DM from the burden of self-stigmatisation.

\section{Future directions}

As yet, we have no way to measure self-reported diabetesrelated stigma quantitatively for the purposes of investigating the extent of perceived and experienced stigma, correlates and causes of stigma, impact on diabetes outcomes and to evaluate the effectiveness of interventions designed to mitigate stigma. The next step in our programme of research in diabetes-related stigma is to draw on the findings of our qualitative work, reported here and elsewhere, ${ }^{19}$ to develop and validate a self-report tool for measuring diabetes-related stigma for adults with T1DM and T2DM.

Our research suggests that there are significant negative consequences of the stigmatisation of diabetes for the individual. Understanding how to minimise the societal stigmatisation of T1DM and T2DM, and how to mitigate the personal effects of stigmatisation are also valuable avenues for future exploration.

\section{Strengths and limitations}

The current study facilitated in-depth explorations of the topic and produced a rich qualitative data set. Purposive sampling resulted in a mix of genders, age ranges, treatment types and socioeconomic and ethnic backgrounds, to maximise the representativeness of the findings. However, people born outside Australia and those living in rural/regional areas were underrepresented in our sample, and participants with a tertiary education and those using an insulin pump were over-represented. ${ }^{21}$ In addition, all participants were members of DA-Vic, the state's consumer organisation.
Consequently, our sample of adults with T1DM may be more engaged in their diabetes care and aware of diabetes issues than the general population of adults with T1DM.

Throughout the data gathering and analysis process, we were cognisant of the potential impact of the researchers' backgrounds, experiences and expectations on knowledge generation. Our expertise in health and clinical psychology, our prior knowledge about diabetes stigma (based on our previous research and literature review), and our informal interactions with people with T1DM that have occurred outside of the bounds of this research project are all likely to have impacted our understanding of the data. Through reflexive and critical discussion among the research team, we have sought to arrange and interpret the data in a way that most closely represents the reality of the study participants.

\section{CONCLUSIONS}

Australian adults with T1DM perceive and experience T1DM-specific stigma as well as stigma-by-association with T2DM. The negative consequences of this stigma span numerous life domains, including relationships and social identity, emotional well-being and behavioural management of T1DM. This stigma also led to reluctance to disclose the condition in various environments. Adults with T1DM can be both the target and the source of diabetes-related stigma. Developing a questionnaire for the quantitative measurement of self-reported diabetesrelated stigma is our next research priority, to enable researchers and clinicians to investigate the extent of such stigma in the wider diabetes population, as well as correlates, causes and consequences of such stigma.

\section{Author affiliations}

${ }^{1}$ The Australian Centre for Behavioural Research in Diabetes, Diabetes Australia-Vic, Melbourne, Victoria, Australia

${ }^{2}$ Centre for Mental Health and Wellbeing Research, School of Psychology, Deakin University, Burwood, Victoria, Australia

${ }^{3}$ School of Psychology, Deakin University, Burwood, Victoria, Australia

${ }^{4}$ School of Psychology, Australian Catholic University, Strathfield, New South Wales, Australia

${ }^{5}$ AHP Research, Hornchurch, UK

Acknowledgements The authors thank all the people with diabetes who expressed an interest or took part in this study. The authors also thank Diabetes Australia-Vic, particularly the membership team, for their assistance with recruitment for this study.

Contributors JLB, JS and KM conceptualised the study. AV and JLB conducted the participant interviews. AV checked the transcripts against the audio files. AV, JLB, KM and JS developed the coding framework. AV and JLB conducted the data analysis. JLB prepared the first draft of the manuscript. Al authors contributed to the development of the interview schedule. All authors provided feedback and contributed to subsequent revisions of the manuscript. All authors approved the final version of this manuscript.

Funding This research was supported by a project grant awarded to KM from the Australian Catholic University and through core funding to The Australian Centre for Behavioural Research in Diabetes (ACBRD) derived from partnership between Diabetes Australia—Vic and Deakin University.

Competing interests None. 
Patient consent Obtained.

Ethics approval Deakin University Human Research Ethics Committee.

Provenance and peer review Not commissioned; externally peer reviewed.

Data sharing statement No additional data available.

Open Access This is an Open Access article distributed in accordance with the Creative Commons Attribution Non Commercial (CC BY-NC 4.0) license, which permits others to distribute, remix, adapt, build upon this work noncommercially, and license their derivative works on different terms, provided the original work is properly cited and the use is non-commercial. See: http:// creativecommons.org/licenses/by-nc/4.0/

\section{REFERENCES}

1. Link BG, Phelan JC. Conceptualizing stigma. Annu Rev Sociol 2001;27:363-85.

2. Weiss MG, Ramakrishna J, Somma D. Health-related stigma: rethinking concepts and interventions. Psychol Health Med 2006;11:277-87.

3. Valdiserri RO. HIV/AIDS stigma: an impediment to public health. $A m$ $J$ Public Health 2002;92:341-2.

4. Brown L, Macintyre K, Trujillo L. Interventions to reduce HIV/AIDS stigma: what have we learned? AIDS Educ Prev 2003;15:49-69.

5. Mahajan AP, Sayles JN, Patel VA, et al. Stigma in the HIV/AIDS epidemic: a review of the literature and recommendations for the way forward. AIDS 2008;22:S67-79.

6. Agerström J, Rooth D-O. The role of automatic obesity stereotypes in real hiring discrimination. J Appl Psychol 2011;96:790-805.

7. Diedrichs PC, Barlow FK. How to lose weight bias fast! Evaluating a brief anti-weight bias intervention. Br J Health Psych 2011;16:846-61.

8. MacLean L, Edwards N, Garrard M, et al. Obesity, stigma and public health planning. Health Promot Int 2009;24:88-93.

9. Puhl RM, Heuer CA. Obesity stigma: important considerations for public health. Am J Public Health 2010;100:1019-28.

10. Hayward P, Bright JA. Stigma and mental illness: a review and critique. J Ment Health 1997;6:345-54.

11. Link BG, Yang LH, Phelan JC, et al. Measuring mental illness stigma. Schizophrenia Bull 2004;30:511-41.

12. Corrigan PW, Miller FE. Shame, blame, and contamination: a review of the impact of mental illness stigma on family members. J Ment Health 2004:13:537-48.

13. Corrigan P. How stigma interferes with mental health care. Am Psychol 2004;59:614.

14. Couture S, Penn D. Interpersonal contact and the stigma of menta illness: a review of the literature. J Ment Health 2003;12:291-305.

15. Winkley K, Landau S, Eisler I, et al. Psychological interventions to improve glycaemic control in patients with type 1 diabetes: systematic review and meta-analysis of randomised controlled trials. BMJ 2006;333:65.

16. International Diabetes Federation. IDF Strategic Plan 2013-2015. Brussels: IDF, 2013.
17. Nicolucci A, Kovacs Burns K, Holt RIG, et al. Diabetes attitudes, wishes and needs second study (DAWN2 ${ }^{\mathrm{TM}}$ ): cross-national benchmarking of diabetes-related psychosocial outcomes for people with diabetes. Diabetic Med 2013;30:767-77.

18. Schabert J, Browne JL, Mosely K, et al. Social stigma in diabetes: a framework to understand a growing problem for an increasing epidemic. Patient 2013;6:1-10.

19. Browne JL, Ventura A, Mosely K, et al. 'I call it the blame and shame disease': a qualitative study about perceptions of social stigma surrounding type 2 diabetes. Br Med J Open 2013;3: e003384.

20. Boyatzis RE. Transforming qualitative information: thematic analysis and code development. Thousand Oaks, CA: Sage, 1998.

21. Speight J, Browne JL, Holmes-Truscott E, et al. Diabetes MILESAustralia (management and impact for long-term empowerment and success): methods and sample characteristics of a national survey of the psychological aspects of living with type 1 or type 2 diabetes in Australian adults. BMC Public Health 2012;12:120.

22. Fernandes PT, Salgado PC, Noronha ALA, et al. Prejudice towards chronic diseases: comparison among epilepsy, AIDS and diabetes. Seizure 2007;16:320-3.

23. Tajfel $\mathrm{H}$, Turner JC. An integrative theory of intergroup conflict. In: Austin WG, Worchel S, eds. The social psychology of intergroup relations. Monterey, CA: Brooks/Cole, 1979:33-47.

24. Dovidio JF, Gaertner SL, Kawakami K. Intergroup contact: the past, present, and the future. Group Processes Intergroup Relations 2003;6:5-21.

25. Berk M, Berk L, Dodd S, et al. The sick role, illness cognitions and outcomes in bipolar disorder. J Affect Disord 2013;146: $146-9$.

26. Ruiter RA, Kok G. Planning to frighten people? Think again. In: Abraham C, Kools M, eds. Writing health communication: an evidence-based guide for professionals. London: Sage, 2012:117-33.

27. Peters G-JY, Ruiter RA, Kok G. Threatening communication: a critical re-analysis and a revised meta-analytic test of fear appeal theory. Health Psychol Rev 2013;7:S8-31.

28. Leckie AM, Graham MK, Grant JB, et al. Frequency, severity, and morbidity of hypoglycemia occurring in the workplace in people with insulin-treated diabetes. Diabetes Care 2005;28:1333-8.

29. Milton B, Holland P, Whitehead M. The social and economic consequences of childhood-onset type 1 diabetes mellitus across the lifecourse: a systematic review. Diabetic Med 2006:23:821-9.

30. Singh $\mathrm{H}$, Cinnirella M, Bradley $\mathrm{C}$. Support systems for and barriers to diabetes management in South Asians and Whites in the UK: qualitative study of patients' perspectives. Br Med J Open 2012;2:pii: e001459.

31. Aikins AdG. Reframing applied disease stigma research: a multilevel analysis of diabetes stigma in Ghana. J Community Appl Soc 2006;16:426-41.

32. Corrigan PW, Watson AC. The paradox of self-stigma and mental illness. Clin Psychol Sci Pr 2002;9:35-53.

33. Mak WW, Cheung RY, Law RW, et al. Examining attribution model of self-stigma on social support and psychological well-being among people with HIV+/AIDS. Soc Sci Med 2007;64:1549-59. 